\title{
A Brief Analysis of Past Temporal and Aspect "Le" and "Guo" in Chinese Compared with English
}

\author{
Shengyu Tian \\ Tiangong University, Tianjin, China \\ Email: arisswift@163.com
}

How to cite this paper: Tian, S.Y. (2021) A Brief Analysis of Past Temporal and Aspect "Le" and "Guo" in Chinese Compared with English. Open Access Library Journal, 8: e7346.

https://doi.org/10.4236/oalib.1107346

Received: March 24, 2021

Accepted: April 23, 2021

Published: April 26, 2021

Copyright $\odot 2021$ by author(s) and Open Access Library Inc.

This work is licensed under the Creative Commons Attribution International License (CC BY 4.0).

http://creativecommons.org/licenses/by/4.0/

\begin{abstract}
This paper attempts to explore the similarities and differences between Chinese and English tenses from the past tense of Chinese and English. Here, the author of this paper chose to use "Le" and "Guo" in Chinese and three temporal situations in English, that is, the Past Simple tense, the Past Progressive tense, and the Past Perfect tense for comparative analysis.
\end{abstract}

\section{Subject Areas}

Linguistics

\section{Keywords}

Tense and Aspect, Chinese and English, Comparative Analysis

\section{Introduction}

Over years, there have been debates about if the Chinese language is a temporal language. Because Chinese is different from English, Chinese has no obvious temporal sign, some scholars Dai (1994) [1], Klein (2009) [2], Lin (2012) [3], Cao (2017 [4], 2019 [5]) also think that Chinese is a kind of "non-temporal language" or "semi-temporal language".

English tense manifestation is through the inflection of verbs, but in Chinese it is a different situation. In Chinese we usually do not change the forms of words, but to add another character before or after, that is, it does not directly change the forms of verbs but adds more semantical components or temporal components in the forms of Chinese character, these forms cannot express the complete meaning by themselves. 
In the author of this paper's opinion, temporal or tense is actually a compound concept, which combines the concepts of time itself and another concept of aspect, aspect is that the state of the action, whether it is completed or not, whether it is in progressive or not. In the first chapter of this paper, the concept of time and aspect was discussed. In the second chapter, it discussed the Chinese temporal and English temporal. Because Chinese has no temporal marker, but it has tense components, it focuses on the language forms of "Le 1", "Le 2", "Guo 1 " and "Guo 2" (in order to differentiate the usages of "Le" and "Guo", here it uses " 1 " and " 2 " following "Le" and "Guo" to distinguish them). The third chapter drew a conclusion through the comparative analysis of Chinese temporal and English temporal.

\section{Concept of Tense and Aspect}

The definition given in Wikipedia is, in grammar, tense is a category that expresses time reference (Bybee 2019 [6], Comrie 1985 [7]). Tenses are usually manifested by the use of specific forms of verbs, particularly in their conjugation patterns. The main tenses found in many languages include the past, present, and future. Some scholars Park (2019) [8], Comrie (1985) [7], Gao (1986) [9] believe that tense is a change of the way an event exists in different time domains, while others Chen (2002) [10], Shi (1994) [11] believe that it belongs to the category of lexical level.

But the Chinese words related to tenses are not only verbs or actions, but also some adjectives, for example:

Guoyuanli de pingguo hongle. (The apples in the orchard are red).

The meaning of this sentence is the process of "orchard apple" from "not red" to "red". Only from the word "red", strictly speaking, it is not a verb. If we regard it as the omission of action of "turning red", or simply as an adjective, we will discuss it later.

\subsection{Tense (Time)}

The concept of time, it can be roughly divided into past, present and future. The past period, based on a certain point of time, can be divided into the Past 1 and the Past 2. If you think of timeline as a stream that can only go forward, then these four periods can be expressed as Past 1, Past 2, Present, and Future.

The past time is before the present time and the future time is after the present time. The future tense is actually an assumption because it has not happened yet. Let's look at an example:

Example 1. Ta zuo tian qu le Shanghai. (He went to Shanghai yesterday).

Example 2. Ming tian ta hui lai. (He will come tomorrow).

Example 3. Ta lai zhi qian yi jing chi fan le. (He had eaten (meal) before he came here)

In Example 1, if the time when the speaker speaks are the present, then the time before speaking is the past, and the time after speaking is the future. If a 
certain time yesterday is taken as reference point, that is, the time when the speaker went to Shanghai, then the past 1 can be defined as before the time when he went to Shanghai yesterday, and past 2 is defined as time segment which is from the time when he went to Shanghai yesterday to the time when the speaker speaks.

In Example 2, it is a kind of hypothesis or speculation about what will happen in the future, which belongs to a period of time in the future. That is to say, the time before speaking belongs to the past, the time when speaking belongs to the present, and the time after speaking belongs to the future.

In Example 3, there is obvious referent time, namely the time he came here, we could easily recognized it as past 1 which is before the time when he came here, and during this period of time, he had eaten (meal). The present is the time when the speaker speaks, which is implied information in the conversation. Past 2 is from the time when he ate meal to the time when he came here.

\subsection{Aspect}

Aspect is a grammatical category that describes the relationship among movement situation, state and timeline which is manifested by all forms of verbs. It mainly describes whether the action is continuous or not, whether it is completed or not, and whether it emphasizes the action itself or not. Generally speaking, it is relatively complex. Although the concept of aspect is related to verbs, it is also related to the category of words and logic, as well as the emotion and mentality of the speaker. For example, in these sentences, it expresses different states of action, "Ta kan le shu. (He read the book.)", it means the action has completed; "Ta (zuo tian) zheng zai kan shu. (He was reading the book.)", it means that the action is happening now and theoretically speaking, the action "reading" can last for a relative long time; "Ta yi jing kan shu le. (He had read the book).", it means that the action was completed and it is in the past.

\section{Chinese and English Temporal}

Because of the previous statement of the concept of time and aspect, the discussion of Chinese tense and English tense will be mainly analyzed and explored from these two aspects. Chinese is paratactic language, English is hypotactic language. Different from English, there is no obvious tense marker in Chinese, which is mainly embodied by the language forms of "Le", "Guo" and "Lai zhe". Here we mainly discuss "Le" and "Guo". When it comes to "Le", there are two situations: one is directly added after the verb, which we call "Le 1"; the other is added at the end of the sentence, which we call "Le 2". Some scholars believe that the language form of "Guo" can be divided into two kinds: "Guo 1" (meaning the end of the action) and "Guo 2" (meaning that there has been such a thing before).

\subsection{Chinese}

1) “Le 1" "Le 2" 
In Chinese, the past tense can be expressed by "Le", but in fact, "Le" can be divided into two kinds of situations: 1) "Le 1" means that an event begins to occur at a certain time in the past, ends at a certain time in the past, and has completed or ended at the time of speaking, usually it is added after the verb. 2) "Le 2 " means that an event starts from the time of speaking, and it has not finished yet, usually it is added at the end of the sentences. For example:

Example 1. Ta chi le fan. (He had dinner.)

Example 2. Ta chi fan le. (He has a meal.)

Example 3. Ta chi le fan le. (He had eaten.)

Firstly, "le" is not a verb. In Example 1, "he" started eating in the past 1 and at end of the past 2 he finished eating, and has ended when the speaker speaks, that is, the "eating" action has been completed. In Example 2 "he" starts eating from now on, and it is not finished and still in progress. Moreover, the author of this paper thinks that Example 2 implies that "he" may not be willing to eat but now "he" is willing to. In Example 3 "he" had eaten from the past 1, and ends when the speaker speaks, which is the present, and implies the impact on the present (already full).

Although Example 1 and Example 3 have similar semantic meanings, there are subtle differences: 1) the ending time of action is different, the ending time of Example 1 action is the past 1, and the ending time of Example 3 is now. In other words, "le 1" implies that the completing time is now, while "le 2" indicates past. 2) In Example 3, due to "le 2" implying the completing time is past, the action "eating" in Example 3 is just finished or the speaker thinks it is just finished, while Example 1 is that the action of "eating" has been finished for a long time or the speaker thinks it has been "full" for a long time, due to the "le 1 "

Let's look at another a set of examples:

Example 4. Ta zai Beijing zhu le san nian. (He lived in Beijing for three years.)

Example 5. Ta zai Beijing zhu le san nian le. (He has lived in Beijing for three years.)

In addition to the differences mentioned above, 4 means "he" has lived in Beijing for three years from the past 1 to the past 2, and now he is no longer in Beijing; Example 5 means "he" has lived in Beijing for three years from the past to now, and now he is still in Beijing.

By comparing the two verbs "live" and "eat", we can find that "eat" is a short-lasting verb, which usually does not take a long time to complete the action of "eat"; while "live" can be a long-term and theoretically lasting action. This is related to the category of verbs and logical relationship that we mentioned earlier.

Another example:

Example 6. Ji dan shu le. (The eggs have been cooked).

Example 7. Zhe ben shu wo kan le. (I have read this book).

Example 8. Ta yi jing zhi dao le na ge xiao xi. (He already knew the news). 
Example 6 means that "eggs" have changed from "raw" to "cooked", that is, they used to be "raw" but now they are "cooked". If we change the sentence to "The egg has been uncooked", it is unreasonable, because the sentence means that the egg used to be "cooked", but now "not cooked"; Once the egg is cooked, it is irreversible, so the sentence is wrong. This is the same as the "red" question mentioned earlier. The meaning of "cooked" and "Le 1" is compatible, so they can be used together. Example 8 means that "he" started to know the news in the past 1 , and the action has ended in the past 2 and the action was completed instantly. But unlike Example 7, "he" will be informed of the news when the speaker is speaking, but in Example 7 the action of "reading" has finished when speaking, and will not continue to read. But if you think about it carefully, although the action of "read" has been completed, the content of the book has been understood by "I", the state of "book" being read out, why is there such a difference? This is a question which deserved considerations.

2) "Guo"

The author of this paper thinks that the meaning of "Guo" is almost the same as that of "Le". Here's an example:

Example 9. Ta zai Beijing zhu le san nian. (He lived in Beijing for three years.)

Example 10. Ta zai Beijing zhu guo san nian. (He lived in Beijing for three years.)

Example 11. Ta zai Beijing zhu le san nian le. (He has lived in Beijing for three years.)

Example 12. Ta san nian qian jiu zai Beijing zhu zhe. (He lived in Beijing three years ago.)

The above sentences 9 and 10, 11 and 12 have the same meaning.

In addition, from the perspective of interrogative sentences, the following three sentences have the same meaning.

Example 13. Ta kan le shu ma? (Did he read a book?)

Example 14. Ta kan le shu le ma? (Did he read the book?)

Example 15. Ta kan guo shu le ma? (Did he read the book?)

\subsection{English}

There are 16 tenses in English. The past tense generally includes the past simple tense, the past continuous tense and the past perfect tense. For example, in English, the past tense changes the verb into the past tense; the past continuous tense changes the auxiliary verb into the past tense and the verb into the continuous tense; the past perfects tense changes the auxiliary verb into the past tense and the verb into the past participle. For example:

Past Simple: He read the book.

Past Continuous: He was reading the book.

Past Perfect: He had read the book.

Since the tenses are more obvious in English, we will not repeat them here.

Let's make a comparison between Chinese and English in reading as an example: 
Tense: $\quad$ English Chinese

Past Simple: He read the book. Ta kan le shu.

Past Progressive: He was reading the book. Ta (zuo tian) zheng zai kan shu.

Past Perfect: He had read the book. Ta yi jing kan shu le.

By comparing the past simple tense, the past progressive tense and the past perfect tense in English and Chinese, we can find that the tense in English is very clear, and the tense can be recognized easily by the form of the verb. In Chinese, the aspect of the verb "kan" has not changed from any tense, that is, "kan" is always "kan", while "read" has experienced "read(past tense)", "was reading" and "had read". But similarly, some objective laws or rules cannot use the past tense, such as in the sentence "three plus three is six", because we cannot say "three plus three was six", or "he died for three days", which is unreasonable and illogical.

in Chinese "zheng zai", "le" is added to express that state of this event and especially in the sentence "Xiao ming zuo tian zheng zai kan shu (Xiaoming was reading books yesterday)", if we want to express past progressive in Chinese, then a past time point must be added like "zuo tian (yesterday)". But in English "was reading" is an expression that specifically means a progressive action took place in the past without adding time adverbial, which does not mean any specific time (Here it used "zuo tian (yesterday) to ensure the semantic equivalence in English and Chinese”).

\section{Conclusion}

We can draw a conclusion that Chinese, as a language without tense sign, is mainly marked by the words or language forms such as "Le", "Guo", "Lai zhe", "Zheng zai" and "Yi jng". Some of the words or language forms cannot be used with other words or language forms. For example, we can say that "Ji dan zhu shu le (The eggs are boiled)", but "Ji dan zhu sheng le (The eggs are boiled raw)". "Le 2" cannot be used with the word "ming tian (tomorrow)" to express the things that will happen in the future. For example, "Ming tian xia yu le (It have rained tomorrow)", which is inconsistent with the meaning of "Le 2". "Le 1" cannot be said like this: Ta si le san tian. (He died for three days), because people cannot come back to life after death. In English, tenses are more obvious. Chinese logic and English are interlinked. However, from the aspect of its forms of expression, English tenses develop and change with the person of the language subject and the relationship with the time. At the same time, there are also many requirements for change, such as details, formalization and regularization. Compared with the language form of Chinese, this change of tense and form is in a relatively stable state.

\section{Conflicts of Interest}

The author declares no conflicts of interest regarding the publication of this paper. 


\section{References}

[1] Dai, Y.J. (1994) On Functions of -le in Future Sentence. In: Yu, Z.H., Ed., Modern Linguistics: New Horizons of Theoretical Construction, Language and Literature Press, Beijjing, 114-122.

[2] Klein, W. (2009) How Time Is Encoded. In: Wolfgang, K. and Li, P., Eds., The EXpression of Time, Mouton de Gruyter, Berlin /New York, 39-82. https://doi.org/10.1515/9783110199031.39

[3] Lin, J.-W. (2012) Tenselessness. In: Binnick, R., Ed., The Oxford Handbook of Tense and Aspect, Oxford University Press, New York.

[4] Cao, D.G. and Xu, L.C. (2017) The Study of Genuine Tenseless Languages. Contemporary Linguistics, 1, 93-121.

[5] Cao, D.G. and Xu, L.C. (2019) Is Mandarin Chinese a (Semi-) Tensed Language? Contemporary Linguistics, 3, 451-465.

[6] Bybee, J.L., Perkins, R. and Pagliuca, W. (2019) The Evolution of Grammar: Tense, Aspect, and Modality in the Languages of the World. University of Chicago Press, Chicago.

[7] Comrie, B. (1985) Tense. Cambridge University Press, Cambridge. https://doi.org/10.1017/CBO9781139165815

[8] Minah, P. and Yuan, Y.L. (2019) Is Mandarin Chinese a Tenseless Language? Contemporary Linguistics, 3, 438-450.

[9] Gao, M.K. (1986) On Chinese Grammar. The Commercial Press, Beijing.

[10] Chen, L.M. (2002) Tense and Tense Components in Chinese. Language Study, 3, 14-31.

[11] Shi, Y.Z. (1994) Aspect in Modern Chinese. Social Sciences in China, 2, 156-173+224. 